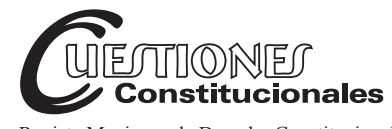

Revista Mexicana de Derecho Constitucional Núm. 43, julio-diciembre 2020

\title{
Hacia una sistematización de los usos semánticos del concepto de dignidad humana en la protección internacional de derechos humanos: una revisión doctrinaria*
}

\author{
Towards a systematization of the semantic uses of the concept \\ of human dignity in the international protection of human rights: \\ a doctrinal review
}

\section{Jorge Nicolás LAFFERRIERE** Helga LELL***}

\begin{abstract}
RESUMEN: este artículo se enmarca en un proyecto de investigación que indaga en la multiplicidad semántica que reviste el término "dignidad" en los casos contenciosos y en las opiniones consultivas de la Corte Interamericana de Derechos Humanos. Ello implica partir de la hipótesis de que dicha variedad de significados existe, y de que el análisis de este tópico es relevante, por cuanto permite clarificar el impacto de las posturas tomadas sobre la concreción de derechos.
\end{abstract}

ABSTRACT: This article is part of a research project that analyzes the semantic variety that have been provided to the term "dignity" in cases and opinions of the InterAmerican Court of Human Rights. This implies departing from the hypothesis that this variety of meanings exists and that the study of this topic is relevant because it allows clarifying the impact of the positions taken on concreting rights.

* Este trabajo se enmarca en el PICTO-UCA 2017-0032 “El concepto de Dignidad Humana según la Corte Interamericana de Derechos Humanos. Análisis de los casos contenciosos y de las opiniones consultivas", cofinanciado por ANPCyT y UCA (Argentina). Los aportes de los integrantes del equipo de investigación han hecho este trabajo posible.

** Pontificia Universidad Católica Argentina, Facultad de Derecho, director del proyecto PICTO 2017-0032; profesor titular ordinario. Universidad de Buenos Aires, Facultad de Derecho, profesor regular adjunto. Argentina. ORCID: 0000-0003-2600-2226 Correo electrónico: jorgelafferriere@derecho.uba.ar.

*** CONICET; Universidad Nacional de La Pampa, Facultad de Ciencias Económicas y Jurídicas, Centro de Investigación en Ciencias Jurídicas. Argentina. Integrante del proyecto PICTO 2017-0032. Argentina. ORCID:0000-0001-7703-634. Correo electrónico: helgalell@cpenet.com.ar. 
El trabajo que aquí presentamos constituye una primera aproximación al estado de la cuestión a partir de una revisión de las posiciones doctrinarias respecto de qué significados puede tener el término "dignidad", con especial referencia a las normas e interpretación jurisprudencial en el ámbito de los derechos humanos. Esta revisión es útil para realizar una propuesta de sistematización y clasificación de esos posibles usos para futuros trabajos de investigación jurisprudencial.

Palabras clave: dignidad, Corte Interamericana de Derechos Humanos, semántica, sistematización.
The paper we present here constitutes a first approach to the state of the matter from a review of the doctrinal positions regarding which meanings the term "dignity" may have. To do so, we emphasize in norms and jurisprudence in the matter of human rights. This review is useful in order to make a proposal for systematization and classification of these possible uses for future research work.

Keywords: dignity, Inter-American Human Rights Court, semantics systematization.

\begin{abstract}
SUMARIO: I. Introducción. II. La noción de "dignidad" en los documentos de protección de derechos humanos. III. Estudios doctrinarios sobre el uso de la dignidad en los cuerpos normativos. IV. Los usos de la dignidad por el Tribunal Europeo de Derechos Humanos. V. Estudios doctrinarios sobre la dignidad en el sistema interamericano de derechos humanos. VI. Estudios sobre los usos de la dignidad por los tribunales nacionales. VII. Una propuesta de sistematización de los usos de la dignidad. VIII. Consideraciones finales. IX. Referencias bibliográficas.
\end{abstract}

\title{
I. INTRODUCCIÓN
}

En el derecho internacional de los derechos humanos, la noción "dignidad humana" ocupa un lugar central. El sistema interamericano de derechos humanos (en adelante "Sistema IDH") no es una excepción, y la dignidad es mencionada en los más importantes cuerpos normativos. A pesar de ello, la forma abstracta en la que se enuncia pareciera dar lugar a una falta de claridad en lo que quiere denotarse mediante este término. Aunque su uso es constante, el significado de esta unidad lingüística sería un campo de crecientes disputas — que, además, muchas veces no parecieran ser conscientes o intencionales-. 
Este artículo se enmarca en un proyecto de investigación que indaga en la multiplicidad semántica que reviste el término "dignidad" en los casos contenciosos y en las opiniones consultivas de la Corte Interamericana de Derechos Humanos (en adelante, Corte IDH). Por supuesto, ello implica partir de la hipótesis de que dicha variedad de significados existe, y de que el análisis de este tópico es relevante, por cuanto permite clarificar el impacto de las posturas tomadas sobre la concreción de derechos. El proyecto de investigación se orienta a contribuir con una sistematización de los distintos significados que recibe la expresión "dignidad humana" en los usos por parte de la Corte IDH y la realización de una propuesta hermenéutica superadora que dé unidad a la utilización argumentativa del termino. Al ser un valor fundante, el hecho de que su semántica no sea clara generaría un problema en la comprensión de los derechos vigentes en el sistema, y, por ello, reclama un estudio sistemático del lugar que ocupa la dignidad humana en el discurso jurídico de la Corte IDH.

Las dificultades en la aplicación de la noción de dignidad, por la disparidad de criterios en torno a su significado, han generado una fuerte tensión en torno a su alcance y utilidad. ${ }^{1}$ Para Waldron, no es sorprendente que haya disenso sobre la caracterización de la dignidad, y ello no menoscaba la idea de que dicho valor es fundamento de derechos humanos, pues considera que se trata de un proceso o trabajo en elaboración que nos lleva a prestar atención a preguntas sobre los derechos. ${ }^{2}$ En tal sentido, no ingresaremos aquí en el debate de fondo sobre el fundamento de la dignidad. ${ }^{3}$

En ese contexto, el trabajo que aquí presentamos constituye una primera aproximación al estado de la cuestión a partir de una revisión de las

1 Calo, Zacharie "Human Dignity and Health Law: Personhood in recent bioethical debates", Notre Dame Journal Laaw Ethics \& Pub, vol. 1, núm. 2, 2012, pp. 473-499; Dilley, Stephen y Palpant, Nathan, Human Dignity in Bioethics: From Worldviews to the Public Square, Londres, Routledge, 2012; Andorno, Roberto, "The Paradoxical Notion of Human Dignity”, Rivista Internazionale di Filosofia del Diritto, vol. 78, núm. 2, 2001, pp. 151-168; Kateb, George, Human Dignity, Cambridge, Harvard University Press, 2011; Meltzer Henry, Leslie, "The Jurisprudence of Dignity", University of Pennsylvania Law Review, vol. 160, núm. 1, 2011, pp. 169-233.

2 Waldron, Jeremy, “Is Dignity the Foundation of Human Rights?”, NYU School of Law, Public Law Research Paper, 12-73, 2013, pp. 1-30.

3 Sobre este tema remitimos a otros estudios: Herrera, Daniel, La persona y el fundamento de los derechos humanos, Buenos Aires, EdUCA, 2012, pp. 333-337; Massini Correas, Carlos Ignacio, Filosofía del Derecho, I - El derecho, los derechos humanos y el derecho natural, 2a. ed., Buenos Aires, Lexis-Nexis, 2005, pp. 138-141. 
posiciones doctrinarias respecto de qué significados puede tener el término "dignidad", con especial referencia a las normas e interpretación jurisprudencial en el ámbito de los derechos humanos. Ello contribuye a comprender la complejidad del tema, no sólo para el sistema interamericano, sino para todo tipo de estudio o aplicación jurídica que involucre a esta noción. De esta manera, las próximas páginas anticipan las clasificaciones que distintos autores han postulado a la luz de la interpretación de documentos jurídicos internacionales y constitucionales.

En una primera instancia, nos detendremos en una rápida enumeración acerca de cómo la noción de "dignidad" aparece en los principales instrumentos de derechos humanos. En segundo término, efectuaremos el recorrido por las presentaciones doctrinarias referidas a los usos de la dignidad en general, distinguiendo los estudios centrados en el análisis de los cuerpos normativos, y los estudios que se dedican al Tribunal Europeo de Derechos Humanos, al sistema interamericano de derechos humanos y a los tribunales nacionales. Esta revisión del estado de la cuestión nos servirá para realizar una propuesta de sistematización y clasificación de esos posibles usos para futuros trabajos de investigación jurisprudencial.

\section{LA NOCIÓN DE “DIGNIDAD” EN LOS DOCUMENTOS DE PROTECCIÓN DE DERECHOS HUMANOS}

La noción de "dignidad" aparece en gran parte de los documentos tutelares de derechos humanos a nivel internacional, ${ }^{4}$ tanto en aquellos que poseen naturaleza vinculante para los Estados parte como para aquellos que constituyen soft law. A continuación, nos detendremos brevemente en algunos de los principales instrumentos en los diferentes sistemas.

En el marco del sistema universal de los derechos humanos, la dignidad es mencionada en diversas oportunidades con un sentido semejante: como un elemento propio de la naturaleza humana. Ya en la Carta de las Naciones Unidas 5 aparece mencionada en el preámbulo cuando reafirma "la fe en los derechos fundamentales del hombre, en la dignidad y el valor de la

4 Gros Espiell, Héctor, "La dignidad humana en los instrumentos internacionales sobre derechos humanos", Anuario de Derechos Humanos, nueva época, 4, 2003, pp. 193-223.

5 ONU, Carta de las Naciones Unidas (San Francisco, 1945), disponible en https:// www.un.org/es/charter-united-nations. 
persona humana, en la igualdad de derechos de hombres y mujeres y de las naciones grandes y pequeñas". En la Declaración Universal de Derechos Humanos, ${ }^{6}$ aparece en el preámbulo, al señalarse que la libertad, la justicia y la paz tienen por base el reconocimiento de la dignidad intrínseca de los seres humanos, y que los pueblos de las Naciones Unidas han reafirmado su fe en la dignidad de la persona humana. Por otro lado, en el artículo 1 se establece que todos los seres humanos nacen libres e iguales en dignidad; en el artículo 22 se menciona a la dignidad como una guía para la satisfacción de derechos económicos, sociales y culturales, y en el artículo 23, como un estándar al cual adecuar los derechos sociales y laborales. Por otro lado, en el Pacto Internacional de Derechos Civiles y Políticos, ${ }^{7}$ en el Pacto Internacional de Derechos Económicos, Sociales y Culturales, ${ }^{8}$ en la Convención Internacional sobre las Personas con Discapacidad ${ }^{9}$ y en la Convención Internacional sobre los Derechos del Niño ${ }^{10}$ la dignidad figura como una nota inherente al ser humano.

En el sistema europeo, en el artículo 26 de la Carta Social Europea, ${ }^{11}$ se la menciona como una nota del trabajo, y en el preámbulo, en el título I (artículos 1 a 5$)^{12}$ y artículo 31 de la Carta de los Derechos Fundamentales de la Unión Europea, ${ }^{13}$ como una característica propia del ser humano. ${ }^{14}$ Por otro lado, en el Convenio Europeo para la Protección de los Derechos

6 ONU, Declaración Universal de Derechos Humanos, 1948, disponible en: https:// www.un.org/es/universal-declaration-human-rights.

7 ONU, Pacto Internacional de Derechos Civiles y Politicos, 1976, disponible en: https://www.ohchr.org/SP/ProfessionalInterest/Pages/CCPR.aspx.

8 ONU, Pacto Internacional de Derechos Económicos, Sociales y Culturales, 1976, disponible en: https://www.ohchrorg/SP/ProfessionalInterest/Pages/CESCR.aspx.

9 ONU, Convención Internacional sobre los Derechos de las Personas con Discapacidad, 2006, disponible en: https://www.un.org/esa/socdev/enable/documents/tccconvs. $p d f$.

10 ONU, Convención Internacional sobre los Derechos del Niño, 1989, disponible en: https://www.un.org/es/events/childrenday/pdf/derechos.pdf.

11 Consejo de Europa, Carta Social Europea (Estrasburgo, 1961), disponible en: https://www.acnur.org/fileadmin/Documentos $/$ BDL/2002/1934.pdf?file $=t 3 /$ fileadmin $/$ Documentos/BDL/2002/1934.

12 Este título se denomina "Dignidad", y el artículo 1 se refiere específicamente a la dignidad humana.

13 Unión Europea, Carta de los Derechos Fundamentales de la Unión Europea, 2000, disponible en: http://www.europarl.europa.eu/charter/pdf/text_es.pdf.

14 Cabe destacar que el artículo 31 se refiere a la dignidad humana del trabajador. 
Humanos y de las Libertades Fundamentales,${ }^{15}$ este término no aparece, aunque sí es mencionado en los considerandos del Protocolo núm. 13, relativo a la abolición de la pena de muerte en cualquier circunstancia, ${ }^{16} \mathrm{con}$ el mismo sentido que el de la Carta de Derechos Fundamentales.

En el sistema africano, la Carta Africana sobre Derechos Humanos y de los Pueblos ${ }^{17}$ se refiere a la dignidad en su preámbulo en dos oportunidades. En la primera de ellas, menciona que la dignidad (no especifica si se aplica al ser humano como individuo, a condiciones de desarrollo o a las comunidades) es un objetivo esencial para la realización de las legítimas aspiraciones de los pueblos africanos. En la segunda, claramente hace alusión a una nota de los pueblos africanos que luchan "por su dignidad y genuina independencia". Por otro lado, este mismo documento, en el artículo 5, se refiere a la dignidad humana como propiedad de los individuos. La Carta Africana sobre los Derechos y el Bienestar del Niño ${ }^{18}$ menciona a la dignidad en seis oportunidades, todas ellas como un elemento inherente del ser humano y como un valor intangible.

Asimismo, en el sistema americano de tutela de los derechos humanos, en el preámbulo de la Declaración Americana de los Derechos y Deberes del Hombre, ${ }^{19}$ se menciona que todos los hombres nacen libres e iguales en dignidad y derechos, y que si los derechos exaltan la libertad individual, los deberes expresan la dignidad de dicha libertad. Finalmente, en el artículo XXIII se menciona el derecho a la propiedad privada en el marco de una vida decorosa que contribuya a mantener la dignidad de la persona. Para Quintana, “desde una perspectiva filosófica política, pero

15 Consejo de Europa, Convenio Europeo para la Protección de los Derechos Humanos y de las Libertades Fundamentales, 1950, disponible en: https://www.echr.coe.int/ Documents/Convention_SPA.pdf.

16 Consejo de Europa, Protocolo núm. 13 al Convenio para la Protección de los Derechos Humanos y de las Libertades Fundamentales, relativo a la abolición de la pena de muerte en cualquier circunstancia, 2002, disponible en: https://www.echr.coe.int/Documents/Convention_SPA.pdf.

17 Organización para la Unidad Africana, Carta Africana sobre Derechos Humanos $y$ de los Pueblos, 1981, disponible en: https://www.acnur.org/fileadmin/Documentos/ BDL/2002/1297.pdf.

18 Organización para la Unidad Africana, Carta Africana sobre los Derechos y el Bienestar del Niño, 1990, disponible en: https://www.acnur.org/fileadmin/Documentos/ BDL/2010/8025.pdf?view.

19 OEA, Declaración Americana de los Derechos y Deberes del Hombre, 1948, disponible en: http://www.oas.org/es/cidh/mandato/Basicos/declaracion.asp. 
también jurídica, su Preámbulo es un paradigma de sociabilidad difícil de superar". ${ }^{20}$

Por su parte, en el marco de la Convención Americana sobre Derechos Humanos ${ }^{21}$ el término "dignidad" aparece como una nota inherente al ser humano en el marco del derecho a la integridad personal (artículo 5), al mencionar que ésta no debe ser afectada por el trabajo forzoso (artículo 6) y al establecer el derecho a su reconocimiento (artículo 11). Ferrer MacGregor y Pelayo Möller señalan que

si bien en el Preámbulo de la CADH no hay una referencia explícita a la dignidad de la persona humana, fácilmente puede advertirse que este es el sentido de la justificación de los derechos de la Convención a la que se hace referencia en las expresiones "fundado en el respeto a los derechos esenciales del hombre", "los derechos esenciales del hombre no nacen del hecho de ser nacional de determinado Estado" y "tienen como fundamento los atributos de la persona humana". ${ }^{22}$

El Protocolo Adicional a la Convención Americana sobre Derechos Humanos en materia de Derechos Económicos, Sociales y Culturales ${ }^{23}$ menciona a la dignidad en el preámbulo al garantizar su reconocimiento en relación con los derechos económicos, sociales y culturales, por un lado, y los civiles y políticos, por el otro, y en el artículo 13, al remarcar que la educación debe capacitar para lograr una subsistencia digna.

La Convención Interamericana para Prevenir y Sancionar la Tortura ${ }^{24}$ trae a colación la dignidad humana en el preámbulo, al reafirmar que todo acto de tortura o tratos crueles, inhumanos o degradantes constituyen ofensas a ella.

20 Quintana, Eduardo, "Dignidad y deberes humanos", Prudentia Iuris, vol. 83, núm. 2, 2017, p. 91.

21 OEA, Convención Americana sobre Derechos Humanos, 1969, disponible en: https://www.oas.org/dil/esp/tratados_b-32_convencion_americana_sobre_derechos_humanos.htm.

22 Mac-Gregor, Eduardo y Pelayo Möller, Carlos María, "Preámbulo", Convención Americana sobre Derechos Humanos comentada, ed. Christian Steiner y Patricia Uribe, 2014, p. 38.

23 OEA, Protocolo Adicional a la Convención Americana sobre Derechos Humanos en materia de Derechos Económicos, Sociales y Culturales, 1988, disponible en: https:// www.oas.org/juridico/spanish/tratados/a-52.html.

24 OEA, Convención Interamericana para Prevenir y Sancionar la Tortura, 1987, disponible en https://www.oas.org/juridico/spanish/tratados/a-51.html. 
La Convención Interamericana sobre Desaparición Forzada de Perso$\operatorname{nas}^{25}$ y la Convención Interamericana para la Prevención, Sanción y Erradicación de la Violencia ${ }^{26}$ mencionan, en sus respectivos preámbulos, que los delitos a los cuales se abocan constituyen graves ofensas a la dignidad. La Convención Interamericana para Prevenir, Sancionar y Erradicar la Violencia contra la Mujer ${ }^{27}$ menciona el término en tres oportunidades, en dos de ellas en relación con la dignidad como inherente a la naturaleza humana, y en una para hacer referencia a la dignidad de la mujer.

\section{ESTUDIOS DOCTRINARIOS SOBRE EL USO DE LA DIGNIDAD EN LOS CUERPOS NORMATIVOS}

La interpretación del término "dignidad" se presenta como un tema de actualidad y de decisiva significación para el derecho internacional de los derechos humanos. Según Shulztiner y Carmi, la dignidad humana es un concepto central del constitucionalismo posterior a la Segunda Guerra Mundial. ${ }^{28}$ Antes de 1945 sólo cinco países lo tenían en sus Constituciones (México, Weimar, Finlandia, Irlanda, y Cuba), y después de diciembre de 2012, ciento sesenta y dos países lo han incorporado; esto es, el $84 \%$ de los 193 que componen las Naciones Unidas (los primeros tres en incorporarlo fueron Alemania Occidental, Japón e Italia). Estos autores realizan un análisis cuantitativo y cualitativo del término "dignidad" en los textos constitucionales.

Además del estudio del uso del término a lo largo del tiempo, resulta interesante el análisis de las causas o influencias que dieron lugar al incremento del uso del término, entre las que los autores ubican la decisiva influencia de la Carta de las Naciones Unidas y la Declaración Universal de Derechos Humanos, la difusión de la democracia (120 países a fines

\footnotetext{
25 OEA, Convención Interamericana sobre Desaparición Forzada de Personas, 1994, disponible en: https://www.oas.org/juridico/spanish/tratados/a-60.html.

26 OEA, Convención Interamericana para la Prevención, Sanción y Erradicación de la Violencia, 1994, disponible en: https://www.oas.org/juridico/spanish/tratados/a-61.html.

27 OEA, Convención Interamericana para Prevenir, Sancionar y Erradicar la Violencia contra la Mujer, 1994, disponible en: http://www.corteidh.or.cr/sitios/libros/todos/ docs/documentosbasicos2018.pdf.

28 Shulztiner, Doron y Carmi, Guy, "Human Dignity in National Constitutions: Functions, Promises and Dangers", American Journal of Comparative Law, vol. 62, núm. 2, 2014, p. 461.
}

Esta obra está bajo una Licencia Creative Commons

Atribución-NoComercial-SinDerivar 4.0 Internacional, IJJ-UNAM. 
del siglo XX, o sea, el 63\%) y la caída de la cortina de hierro. Entre los motivos del trasplante del término se destacan su prestigio, la presión internacional, una cuestión de ahorro de tiempo, la situación poscolonial y los usos a nivel regional. También hay influencia de quienes no la usan: en especial Estados Unidos, Gran Bretaña y Francia.

Shulztiner y Carmi identifican tres usos de la dignidad en las distintas Constituciones:

a) Simbólico-declarativos: este uso se constata principalmente en preámbulos y declaraciones de principios, y la dignidad aparece como un valor general y un fundamento genérico de toda la Constitución y sin un significado operativo. Entre los ejemplos de este uso ubican a Brasil, Perú y Timor Oriental.

b) Guía para la implementación de derechos: señalan que en el articulado de las Constituciones la dignidad aparece vinculada con derechos para ofrecer una guía a los jueces en sus sentencias. Identifican: i. estipulaciones para preservar la dignidad de personas que tienen una restricción a su libertad (Armenia, Finlandia, Nicaragua, Malawi); ii. Cuestiones laborales (veintitrés países: Portugal, Cabo Verde, Angola, Mozambique, Colombia, Argentina, Paraguay, Costa Rica, Nicaragua, Ecuador, Dominicana, Corea del Sur); iii. Cuestiones vinculadas al bienestar (niños, ancianos, discapacitados) (Timor Oriental, Kenia, Venezuela, Bolivia).

c) Guía para la limitación de derechos: los autores entienden que, en un uso propio de países no democráticos o de países subdesarrollados, se utiliza la dignidad como una fuente de deberes de los ciudadanos. Entienden que es un uso "no liberal" ('illiberal'). Como ejemplos mencionan el Líbano: "La educación es libre en la medida que no interfiera con la dignidad de ninguna religión o credo"; Laos, que utiliza la dignidad para cortapisar el derecho de libre expresión cultural y de los medios de comunicación; Mozambique, que dice que el ejercicio de los derechos está regulado por la ley, que debe velar por la dignidad de la persona humana. Algunos países de la ex-URSS la utilizan para limitar el derecho de propiedad. Israel, Canadá y Alemania la utilizan para restringir el derecho de libre expresión. China, Corea del Norte y Sierra Leona establecen deberes hacia el Estado basados en la dignidad. Bahrain, Kuwait y Tanzania establecen el deber de trabajar de los ciudadanos fundado en la dignidad. 
Para Lucy Michael, las distintas definiciones de dignidad son complementarias, y pueden reconducirse a dos categorías: la dignidad inherente, que es una cualidad o valor que pertenece a todo ser humano sin admitir diferencias, y la dignidad no inherente, que es una condición adquirida y variable según las circunstancias o el comportamiento de una persona. ${ }^{29}$

La dignidad ocupa un lugar central en la Declaración Universal de Derechos Humanos. Entre los muchos autores que se refieren al tema cabe mencionar a Mary Ann Glendon, quien destaca la Declaración como el más importante punto de referencia para la discusión intercultural sobre la libertad y la dignidad humanas en el mundo actual. ${ }^{30}$

En cuanto al término "dignidad" en la Declaración Universal de Derechos Humanos, Glendon resalta el hecho de que en ella la noción en cuestión es considerada como "inherente", es "reconocida", al igual que los derechos, y no concedida, que los seres humanos nacen libres e iguales, dotados de razón y conciencia. Ante la pregunta de si la Declaración tiene un valor último y fundante, Glendon responde que el candidato obvio para tal valor es la dignidad humana, que goza de un lugar de privilegio en el texto: es afirmada al inicio del preámbulo antes que los derechos, tiene prioridad en el artículo 1, y es mencionada en otras tres partes claves. Aunque luego aclara que los redactores de la Declaración eran conscientes de que el principio de la dignidad no poseía una inmunidad especial contra su potencial deconstrucción, y que ningún documento estaba exento del peligro de la manipulación. ${ }^{31}$

En el sistema europeo de derechos humanos, la dignidad ha sido objeto de varios estudios a pesar de que la Convención Europea de Derechos Humanos no contiene expresamente el término "dignidad" en su articulado. En cambio, la Carta de Derechos Fundamentales de la Unión Europea (Carta de Niza, 2000) comienza afirmando en su artículo primero: "La dignidad humana es inviolable. Será respetada y protegida".

Un estudio de relevancia es el realizado por Malvestiti, ${ }^{32}$ quien desarrolla la evolución histórica del concepto de dignidad humana: en una prime-

29 Michael, Lucy, "Defining Dignity and Its Place in Human Rights", The New Bioethics, vol. 20, núm. 1, 2014, pp. 12-34.

30 Glendon, Mary Ann, "Knowing the Universal Declaration of Human Rights", The Notre Dame Law Review Review, vol. 73, núm. 5, 1998, 1153-1190 (p. 1153).

31 Idem.

32 Malvestiti, Bárbara, La dignità umana dopo la "Carta di Nizza”, Napoli-Salerno, Orthotes Editrice, 2015. 
ra etapa, asociada a las edades antigua y medieval, implicaba atribuir una cualidad a alguien que se distinguía del resto; una segunda etapa se inicia con Kant, en el siglo XVIII, donde se la concibe como una característica intrínseca del hombre en cuanto a la racionalidad, como un concepto moral que sigue implicando una distinción entre los seres humanos. Por último, a partir del siglo XX, el concepto de dignidad humana ingresa al ámbito jurídico cuando se pasó del plural (dignidades) al singular "dignidad", entendida como una cualidad intrínseca que pertenece a todo ser humano indistintamente. Así, la dignidad desde el punto de vista jurídico ingresó de la mano de la "igualdad". Para esta autora, la dignidad implica la negación del orden jerárquico, no admite grados, y no se necesita ninguna característica para definirse como un ser portador de dignidad, tan sólo la pertenencia al género humano. Es una dignidad "no relacional".

De acuerdo con Malvestiti, en la Carta de Niza hay tres significados del término "dignidad": como valor, como principio y como derecho. A su vez, desde el punto de vista de la interpretación jurídica, considera que la dignidad puede tener dos sentidos: como fundamento del derecho y como derecho. Finalmente, entiende que hay tres conceptos de dignidad que provienen desde afuera del derecho, pero que informan la interpretación jurídica: dignidad de la persona (implica tutela de la persona, tutela de la humanidad y límite a la autonomía); dignidad social y dignidad del individuo.

Esta autora entiende que la dignidad humana debe considerarse una "norma suprema" del ordenamiento jurídico, y ello puede plasmarse a su vez de tres formas: primero, como norma material suprema; segundo, como norma axiológica suprema fruto del acuerdo de los intérpretes, y tercero, como norma axiológica suprema in re. Para cada modo de concreción la autora muestra regulaciones jurídicas de diferentes Estados y jurisprudencia. ${ }^{33}$

En el marco del sistema interamericano, aunque desde una reflexión predominantemente iusfilosófica, Ilva Myriam Hoyos constata tres modos en que las normas jurídicas y los doctrinarios hacen referencia a la dignidad: 1) la dignidad funcional, es decir, aquella que refiere al merecimiento que corresponde a una persona por los papeles o funciones que desempeña o por las acciones que realiza en la sociedad; 2) la dignidad referida a la autonomía, de raíz kantiana, que adopta una perspectiva moral, y que coin-

\footnotetext{
33 Idem.
} 
cide con la libertad del hombre de hacer uso de su propia razón y determinar el sentido de sus actos responsablemente, y 3) la dignidad referida al ser, entendida como la eminencia que corresponde a la persona, es decir, quien subsiste en una naturaleza que de suyo dice perfección. ${ }^{34}$

Otro estudio, que involucró dieciséis países, advierte que términos como "dignidad humana", "dignidad de todos los miembros de la familia humana", "dignidad individual", "dignidad persona", "dignidad de los seres humanos" y "vida digna", son usados en forma alternativa o acumulativa, sin especificar las razones de su elección. La autora entiende que aunque no hay único significado del término, hay un interés universal en él, porque es capaz de promover y apoyar distintos tipos de reclamos, y ello ofrece una riqueza que es importante para el derecho e incluso la bioética. ${ }^{35}$ Este trabajo destaca cuatro usos de la dignidad como instrumento: i) declarativo para condenar la tiranía de los Estados; ii) para asegurar la efectividad de los derechos subjetivos; iii) para la transformación social; iv) para restringir la libertad. ${ }^{36}$

\section{LOS USOS DE LA DIGNIDAD POR EL TRIBUNAL Europeo DE DERECHOS Humanos}

El término "dignidad", además de figurar en cuerpos normativos, también es utilizado por diferentes instituciones judiciales, en donde los inconvenientes sobre la pluralidad semántica se replican. Así como en el proyecto de investigación en el que este artículo se enmarca se parte de la hipótesis de la no claridad en el uso del concepto, diferentes trabajos académicos describen un fenómeno similar en el Tribunal Europeo de Derechos Humanos (en lo sucesivo, TEDH).

Cabe agregar que existen aproximaciones a este fenómeno desde diferentes perspectivas, que van desde la mirada hermenéutica, ${ }^{37}$ hasta las preocupaciones por la concreción de la protección de los derechos que

\footnotetext{
34 Hoyos Castañeda, Ilva Myriam, De la dignidad y de los derechos humanos, Bogotá, Universidad de la Sabana, 2005.

35 Feuillet-Liger, Brigitte, "The Case for a Limited Use of Dignity as a Legal Principle”, Ius Gentium, núm. 71, 2018, pp. 292 у 293.

36 Idem.

37 Klatt, Matthias, "Juristische Hermeneutik", Handbuch Rechtshilosophie, J. B. Metzler, 2017, pp. 224-230. 
hacen a la dignidad humana, ${ }^{38}$ pasando por otras, como el análisis de las formas de coordinación que se da en el proceso de integración europeo, de manera tal que los organismos supraestatales no arrasen con la soberanía nacional sin por ello dejar de tutelar la dignidad, ${ }^{39}$ o la propuesta de una dimensión interpretativa europea como garantía de $\operatorname{los}$ derechos ${ }^{40}$ y el rol constitucional en los Estados europeos del concepto de dignidad. ${ }^{41}$ Por su parte, otro estudio que tiene como eje el sistema europeo señala tres aspectos de la dignidad que son relevantes jurídicamente: la obligación de respeto, la prohibición de tratar a otros como objetos y la prohibición de relaciones de dominación desproporcionadas entre seres humanos, por su igualdad ontológica. ${ }^{42}$

En cuanto a la multiplicidad de significados, Costa afirma que el TEDH recurre habitualmente a la dignidad como fundamento de su razonamiento legal, y analiza la dignidad en relación con la jurisprudencia a partir de los distintos derechos enunciados en la Convención Europea de Derechos Humanos. Este autor distingue el uso positivo del uso negativo. El primero utiliza la dignidad para reforzar un razonamiento que lleva a sostener la violación de un derecho de la Convención. El segundo, en cambio, recurre a la dignidad para rechazar planteos o pretensiones basados en argumentos que son en sí mismos contrarios a la dignidad. ${ }^{43}$

Un estudio de importancia es el que realizaron Kuteynikov y Boyashov, quienes analizaron 86,000 documentos relacionados con la $\mathrm{CEDH}$

38 Grabenwarter, Christoph y Struth, Katharina, "Justiz-und Verfahrensgrundrechte", en Ehlers, D. (ed.), Europäische Grundrechte und Grundfreiheiten, Göttingen, De Gruyter, 2014, pp. 198-236; Wallace, Helen, "Die Dynamik des EU-Institutionengefüges”, en Jachtenfuchs, M. y Kohler-Koch, B. (ed.), Europäische Integration, Springer Verlag, 2003, pp. 255-285.

39 Fischer, Joschka, "Vom Staatenverbund zur Föderation - Gedanken über die Finalität der europäischen Integration”, Intergation, vol. 23, núm.3, 2000, pp. 149-156.

40 Franzius, Claudio, "Die Europäische Dimension des Gewährleistungsstaates”, Der Staat, vol. 45, núm.4, 2006, pp. 547-581.

41 Federmann, Falco, Die Konstitutionalisierung der Europäischen Union. Überlegungen vor dem Hintergrund des andauernden europäischen Verfassungsprozesses, Köln, Eul Verlag, 2007.

42 Pereira-Menaut, Antonio-Carlo y Pereira-Sáez, María Carolina "Human Dignity and European Constitutionalism. Flatus Vocis or Ratio Decidendi?", Ius Gentium, vol. 52, 2016, pp. 215-234.

43 Costa, Jean-Paul, "Human Dignity in the Jurisprudence of the European Court of Human Rights”, en Understanding Human Dignity, Oxford, British Academy, 2013. 
(sentencias, decisiones, comunicaciones, opiniones consultivas y sumarios legales) publicados desde 1949 hasta 2015, de los cuales 1937 (1.9\%) contenían el término "dignidad" ${ }^{44}$ Según estos autores, el primer caso donde hubo referencia a la dignidad data de 1958, aunque los casos que sí la mencionan durante el siglo XX no superan los doce por año. Los autores constatan un notable incremento de sentencias que mencionan la dignidad a partir de 2000, con un promedio de cien decisiones por año que contienen la palabra "dignidad" entre 2004 y 2014. Las violaciones a la dignidad que fueron motivo de decisión del TEDH se vinculan con los siguientes temas: discriminación por razón de género, etnia o religión; malos o degradantes tratos para presos o personas internadas en hospitales; limitaciones en la libertad de elección del paciente; violaciones del honor y la reputación; trabajos forzados y extradición, expulsión y deportación..$^{45}$

Un estudio particularmente interesante por el efecto que menciona respecto del uso del concepto de dignidad sobre la concepción de los derechos clasificados como absolutos y relativos es el de Grewe, quien se enfoca en las técnicas legales utilizadas para invocar y proteger la dignidad en la jurisprudencia del TEDH. ${ }^{46}$ Desde el inicio, aclara que, en su parecer, la dignidad se invoca especialmente para forjar, fortalecer o ampliar un derecho, pero escasas veces o, más bien, nunca para limitar o "volverse" contra el titular de la dignidad. Grewe basa su análisis en cómo la invocación de la dignidad ha ayudado a borrar la distinción entre derechos absolutos (no derogables, intangibles) y derechos relativos (típica en el contexto europeo por la diferente forma en la que están redactados los artículos que protegen unos y otros derechos en el Convenio Europeo, en el que los derechos relativos están sujetos a cláusulas de limitación).

En relación con derechos que considera "absolutos", como el derecho a la vida (artículo 2), la prohibición de la tortura y tratos inhumanos o degradantes (artículo 3) y la prohibición de la esclavitud, la servidumbre y el trabajo forzoso (artículo 4), afirma la autora que la invocación de la dignidad podría parecer evidente, "natural", e incluso inútil. Sin embargo, sostener esto implica apartarse de la promoción de esos derechos. Esta

44 Kuteynikov, Alexander y Boyashov, Anatoly, "Dignity Before the European Court of Human Rights", en Edward Sieh y Judy McGregor (eds.), Human Dignity: Establishing Worth and Seeking Solutions, London, Palgrave MacMillan UK, 2017, pp. 83-101.

45 Idem.

46 Grewe, Constance, "La dignité de la personne humaine dans la jurisprudence de la Cour européenne des droits de l'homme”, Revue générale du droit, 2014, pp. 1-12. 
última tiene que ver, por un lado, con la ampliación de la protección de los derechos por parte de la jurisprudencia. El alcance del artículo 3 del Convenio Europeo, por ejemplo, se extiende ahora a las extradiciones y a las deportaciones, a las condiciones de detención, al tratamiento de las personas con discapacidades mentales. Por otro lado, la promoción de estos derechos conlleva no sólo una obligación de los Estados de no interferir, sino además una pluralidad de obligaciones positivas. ${ }^{47}$ De esta manera, se sometería a estos derechos implícitamente a un control de proporcionalidad, lo cual los acerca a los derechos relativos. ${ }^{48}$

Por el contrario, la invocación de la dignidad humana en el caso de los derechos relativos (derechos contemplados en los artículos 8, 9, 10 y 11) puede sorprender, pues no parecen ser intangibles ni articular valores fundamentales. Además, la técnica de balancear los derechos en juego (propia del examen de proporcionalidad que se aplica a los derechos relativos) no encaja bien con el concepto de dignidad (que simboliza lo universal, lo inmanente, lo inmutable y objetivo). ${ }^{49}$

Según Grewe, para resolver disputas difíciles, nuevas, "sociales" y complejas, la dignidad humana resulta ser un argumento particularmente propicio en tanto ayuda a enriquecer los derechos o a poner énfasis en sus aspectos sociales. Este argumento suele aparecer en el ámbito del artículo 8 , de protección del hogar, de la vida privada y familiar. La vida privada se extiende a la autonomía de la persona, a su identidad, a los derechos de la personalidad. El hogar tiende a abarcar el derecho a no ser expulsado de la vivienda, al menos en situaciones de precariedad o de estigma racial o étnico.

Grewe sostiene que la invocación de la dignidad en estos casos -incluso en presencia de los derechos absolutos- es impredecible, azarosa, evolutiva. La autora critica el carácter aleatorio de la invocación de la dignidad, y lo relaciona con las doctrinas del margen nacional de apreciación y de consenso regional. Cuando, en su opinión, no existe consenso, el TEDH se niega a utilizar el concepto de dignidad para promover un derecho. Esto se aplica bastante extensamente a los derechos sociales y a las cuestiones relacionadas con el comienzo de la vida o la muerte. Esto no sólo plantea problemas de seguridad jurídica, de coherencia jurispru-

\footnotetext{
47 Idem.

48 Ibidem, p. 5.

49 Ibidem, p. 6.
} 
dencial y de calidad de la argumentación de la sentencia, sino que también crea una tensión adicional en relación con el concepto de la dignidad (Grewe, 2014, pp. 6 y 7).

Finalmente, Grewe analiza la función que cumple la dignidad con relación a la tarea judicial. Así, cuando se trata de la dignidad, el Tribunal debe realizar un arbitraje "horizontal" entre la dignidad y otros valores. Así, entiende que cuando está en juego un valor explícito, el Tribunal ha considerado que es mejor referirse a él directamente. Así, incluso en el caso sobre la negación del holocausto, el TEDH ha preferido centrar su razonamiento en la aplicabilidad del artículo 17 sobre los valores de la paz y de la justicia más que sobre la dignidad. A su vez, hay un arbitraje "vertical" entre el derecho europeo y el derecho nacional, la ley del Estado demandado y los derechos de los particulares, el margen de apreciación y las normas europeas. Se presume que la ley del Estado corresponde a las exigencias de una sociedad democrática. A priori, no hay por lo tanto ninguna razón para dudar de la corrección de la legislación nacional, y mucho menos para decir que no respeta la dignidad humana. Esto se refleja en el margen de apreciación nacional. No obstante, la misión del Tribunal de salvaguardar y de desarrollar los derechos humanos incluye la interpretación dinámica del Convenio, así como la corrección de las leyes nacionales cuando no han respetado suficientemente los derechos individuales. El pluralismo y el respeto de las minorías desempeñan un papel importante a este respecto y dan a la legislación europea su carácter evolutivo. La autora finaliza afirmando que los valores y, en primer lugar, la dignidad humana, intervienen para dar, si es posible, una dirección general a la casuística predominante. Esto hace que sea más fácil entender la naturaleza impredecible e impredecible de la llamada a la dignidad sin excluir la crítica del estado actual de cosas (Grewe, 2014, p. 11)

\section{ESTUDIOS DOCTRINARIOS SOBRE LA DIGNIDAD \\ EN EL SISTEMA INTERAMERICANO DE DERECHOS HUMANOS}

Para el estudio de los usos del término "dignidad" en el Sistema IDH, resulta insoslayable la referencia a Antonio Augusto Cançado Trindade, quien fuera juez y presidente de la Corte IDH, y quien ha publicado como editor un trabajo titulado El respeto a la dignidad de la persona huma- 
$n a .^{50}$ En esa obra, César Landa, expresidente del Tribunal Constitucional de Perú, desglosa las siguientes funciones constitucionales de la dignidad: función legitimadora; ordenadora; temporal; esencial; integradora; limitadora, y libertaria. ${ }^{51}$

También podemos mencionar el estudio de Luis Amezcua sobre la dignidad en la jurisprudencia de la Corte IDH. Este autor analiza los contextos en que el tribunal hizo referencia al concepto de dignidad humana y observa que hasta ese momento, los contextos estaban relacionados en su mayoría con hechos relativos al derecho a la vida, desapariciones forzadas, privación ilegal de la libertad y torturas. Comenta que también se la menciona en casos relacionados con las comunidades indígenas en cuanto a su derecho de circulación y derecho de propiedad, el caso de las minorías lingüísticas, personas con discapacidad mental y los casos atinentes a la violencia sexual. Aunque gran parte de los fallos hasta ese momento tenían que ver con la protección de los derechos civiles y políticos, ya se vislumbraba la inclusión en el debate de los derechos económicos, sociales y culturales. ${ }^{52}$

Sobre el punto que cierra el párrafo anterior, Ibáñez Rivas estudia la dignidad y los derechos económicos, sociales y culturales (DESC) en la jurisprudencia contenciosa de la Corte IDH. Allí, partiendo de la sentencia "Velázquez Rodríguez vs. Honduras", ${ }^{53}$ en que la Corte IDH sostiene que "los derechos humanos son atributos inherentes a la dignidad humana", sistematiza los fallos desde de la distinción entre "protección directa" e "indirecta" de los DESC. ${ }^{54},{ }^{55}$ Sobre la protección directa, a su vez, se re-

50 Cançado Trindade, Anotnio Augusto y Barros Leal, César (eds.), El respeto a la dignidad de la persona humana, Fortaleza, Instituto Brasileño de Derechos Humanos, 2015.

51 Landa, César, "Dignidad de la persona humana", en Cançado Trindade, Anotnio Augusto y Barros Leal, César (eds.), El respeto a la dignidad de la persona humana, Fortaleza, Instituto Brasileño de Derechos Humanos, 2015

52 Amezcua, Luis, "Algunos puntos relevantes sobre la dignidad humana en la jurisprudencia de la Corte Interamericana de Derechos Humanos", Revista Iberoamericana de Derecho Procesal Constitucional, vol. 8, 2007, pp. 339-355.

53 Corte IDH, caso Velásquez Rodríguez vs. Honduras. Reparaciones y costas, sentencia del 21 de julio de 1989, serie C, núm. 7.

54 Esta clasificación no será receptada en aquella que los autores hemos efectuado en el último apartado de este trabajo dado que apunta a cómo la dignidad es utilizada para proteger derechos y no se enfoca en los usos del término en sí.

55 Ibáñez Rivas, Juana María, "La dignidad humana y los derechos económicos, so- 
fiere al artículo 26 de la $\mathrm{CADH}$, por un lado, y a otros derechos humanos con "contenido dual" que permiten la protección directa. En cuanto a la protección indirecta, distingue entre la protección indirecta general y la protección específica de los DESC. ${ }^{56}$ Igualmente, aunque su foco está puesto en el fundamento de la argumentación de la Corte y su vinculación con la igualdad material, cabe señalar la investigación de Mary Beloff y Laura Clérico sobre el derecho a condiciones de existencia digna y la vulnerabilidad en la jurisprudencia de la Corte IDH ${ }^{57}$.

Por su parte, en el estudio de Bohórquez y Román se analizan cinco sentencias de la Corte IDH en torno a la dignidad, y se concluye que "la dignidad aparece no solo como un derecho o un principio reconocido en los tratados internacionales sino además renace como criterio de interpretación a favor del sentido más amplio de los derechos humanos", 58 aunque señalan que aún quedan preguntas sin resolver tanto en el nivel teórico como en una valoración crítica de la jurisprudencia de la Corte IDH. Estos autores identifican tres tensiones en torno al concepto de dignidad: a) entre su carácter natural y artificial; b) entre su carácter abstracto y concreto; c) entre su carácter universal y particular. ${ }^{59}$ Ello supone tres preguntas o paradojas conceptuales de la dignidad: ${ }^{60}$ a) ¿es la dignidad humana un aspecto natural de los seres humanos, o es, por el contrario, un aspecto consensual creado por la voluntad política y legislativa de los Estados?; b) ¿es la dignidad humana un valor abstracto o, por el contrario, es posible definirlo en relación con aspectos concretos de la vida humana?, y c) ¿es la dignidad humana un valor absoluto y universal o, por el contrario, es un

ciales y culturales en la Jurisprudencia contenciosa de la Corte Interamericana de Derechos Humanos", en Cançado Trindade, Antonio Augusto y Barros Leal, César (eds.), El respeto a la dignidad de la persona humana, Fortaleza, Instituto Brasileño de Derechos Humanos, 2015, pp. 183-212.

56 Bohórquez Monsalve y Román, op. cit.

57 Beloff, Mary y Clérico, Laura, "Derecho a condiciones de existencia digna y situación de vulnerabilidad en la jurisprudencia de la Corte InterAmericana", Estudios Constitucionales, vol.14, núm. 1, 2016, pp. 139-178.

58 Bohórquez Monsalve \& Román, op. cit., p. 59.

59 Esta clasificación tampoco es receptada en la que los autores ofrecemos al final de este artículo porque enfatizan en una disquisición filosófica más que en los usos del término.

60 Torralba, Francesc, ¿Qué es la dignidad humana? Ensayo sobre Peter Singer, Hugo Tristram Engelhardt y John Harris, Barcelona, Herder, 2005; Bohórquez Monsalve y Román, op cit. 
valor particular dependiente de contextos históricos, culturales e, incluso, individuales?

Estos autores entienden que, respecto a la tensión entre el carácter natural o consensual de la dignidad, la respuesta varía según se parta desde el iusnaturalismo o del iuspositivismo. Para el iusnaturalismo, la dignidad es un rasgo natural del hombre, que lo tiene por el solo hecho de serlo y desde el momento de la concepción. Es una dignidad dada al hombre por la propia naturaleza o por Dios, independientemente de los accidentes de cada uno. Por el contrario, desde el punto de vista iuspositivista, la dignidad humana aparece como algo artificial, dada en forma consensual por los hombres. La dignidad sería una ficción política, moral y jurídica, realizada para mantener la paz y hacer posible la convivencia entre los hombres.

Respecto al carácter abstracto o concreto de la dignidad, estos autores entienden que hay un concepto abstracto de dignidad que implica considerarla un fin en sí mismo. Así, remiten a Kant, quien sostenía que todo ser humano con razón y libertad para seguir los imperativos morales está dotado por ese hecho de dignidad humana universal. Para los autores, este concepto está vacío de contenido y puede generar problemas a la hora de instrumentarlo en la práctica (por ejemplo, para ciertos trabajos, nivel de educación, etcétera), pues carece de contenido práctico. Por su parte, el concepto concreto, en cambio, ofrece a la dignidad humana aspectos más precisos y con más nivel de verificación; por ejemplo: la libertad de escoger la profesión implica también la garantía de recibir una remuneración justa por ella. Este concepto permite una aplicación práctica. Tiene que ver con la necesidad de que toda definición de dignidad humana pueda relacionarse claramente con aspectos concretos de la misma dignidad humana. En la dignidad humana está presente la idea del buen vivir: nadie aceptaría que fuera definida únicamente en términos formales y abstractos.

Finalmente, el carácter universal de la dignidad humana implica considerar que existe una sola dignidad aplicable a todo individuo, en todo tiempo y lugar. El problema es que si relacionamos este concepto con la idea del buen vivir se daría lugar a una contradicción, ya que para cada cultura "buen vivir" significa algo distinto. Por otro lado, el carácter particular de la dignidad humana consiste en considerar la existencia de muchas dignidades, una para cada grupo social y cultural. Este concepto atiende a las necesidades de cada persona en particular. ${ }^{61}$

61 Bohórquez Monsalve y Román, op. cit.

Esta obra está bajo una Licencia Creative Commons Atribución-NoComercial-SinDerivar 4.0 Internacional, IIJ-UNAM. 


\section{ESTUDIOS SOBRE LOS USOS DE LA DIGNIDAD POR LOS TRIBUNALES NACIONALES}

La doctrina se ha ocupado también de los usos de la dignidad por tribunales nacionales. Uno de los autores más influyentes en este tema es McCrudden, quien elabora un "contenido mínimo" de la dignidad que entiende incluye tres elementos: i) que todo ser humano posee un valor intrínseco, por el solo hecho de ser humano; ii) que este valor intrínseco debe ser reconocido y respetado por otros, y que algunas formas de trato por otros son inconsistentes, o son requeridas, por ese valor intrínseco; iii) reconocer el valor intrínseco de cada individuo requiere entender que el Estado existe para el bien del ser humano individual y no a la inversa. ${ }^{62}$ Este autor constata las diferencias en las concepciones de dignidad en la interpretación judicial, sobre todo entre las concepciones más individualistas y las comunitaristas, sobre el peso y el estatus de la dignidad, sobre la dignidad como soporte de derechos o como limitación de derechos, sobre la posibilidad de renunciar a la dignidad, sobre la dignidad de quién debe considerarse, y sobre quién debe juzgar o proteger la dignidad. ${ }^{63} \mathrm{Con}$ todo, McCrudden se muestra escéptico de que la dignidad pueda servir como base para alcanzar un consenso sustantivo sobre la noción de derechos humanos, en razón del carácter abierto y no específico que tiene el término, de la posibilidad de que sea manipulable y de su aparente universalidad que oculta la importancia de los distintos contextos culturales para determinar su contenido. ${ }^{64}$ Este autor rescata el uso institucional que tiene la dignidad en tanto proporciona un lenguaje en el que los jueces pueden aparecer justificando cómo resuelven tópicos tales como el balance de derechos, la aplicación a nivel local de los derechos y la generación de nuevos derechos. ${ }^{65}$

Rao tiene dos importantes trabajos sobre el tema. En el primero se refiere al uso y el abuso de la dignidad en el derecho constitucional, ${ }^{66} \mathrm{y}$ en

62 McCrudden, Christopher, "Human Dignity and Judicial Interpretation of Human Rights", European Journal of International Law, vol.19, núm. 4, 2008, p. 679.

63 Idem.

64 Ibidem, p. 710.

65 Ibidem, p. 724.

66 Rao, Neomi, "On the Use and Abuse of Dignity in Constitutional Law", Columbia Journal of European Law, 2008, pp. 201-256. 
un posterior estudio señala tres grandes conceptos de dignidad por la revisión de las sentencias de cortes constitucionales: la dignidad como valor inherente a cada individuo independiente de su inteligencia, moralidad o estatus social; la dignidad como expresión de valores sustantivos que se vinculan con formas de vida y conductas en una comunidad (como cuando las cortes en Francia prohíben el espectáculo del lanzamiento de personas enanas), y finalmente el uso de la dignidad como reconocimiento y respeto que implica la comprensión de la pluralidad individual a la luz de los diferentes colectivos que puede integrar un sujeto. ${ }^{67}$

Por su parte, Barroso sistematiza cuatro usos diferentes de la dignidad en la jurisprudencia: como valor fundamental, como principio constitucional, como fuente de derechos y obligaciones y como criterio de interpretación. ${ }^{68}$

Carozza, quien fuera presidente de la Comisión IDH entre 2008 y 2009, considera que el consenso no puede ser un determinante decisivo del mínimo contenido que corresponde al principio de la dignidad humana, y enfatiza la importancia del diálogo sobre el contenido sustantivo de la dignidad, sin quedarse en aspectos meramente procedimentales. ${ }^{69}$

Por su parte, Meltzer Henry identifica cinco concepciones de dignidad en la jurisprudencia de la Corte Suprema de Estados Unidos: ${ }^{70}$ la dignidad como estatus institucional (rango y jerarquía); la igualdad como dignidad; la libertad como dignidad; la integridad personal como dignidad, y la virtud colectiva como dignidad. La dignidad como estatus institucional es un concepto que depende de la existencia de jerarquía social, y se lo utiliza para naciones extranjeras y Estados, en relación con su inmunidad y la imposibilidad de ser llevados a juicio. La dignidad como igualdad se presenta como intrínseca y universal, no contingente. La expresión habitual es la "igual dignidad" de los seres humanos, y su uso ha sido fundante de la jurisprudencia antidiscriminatoria. La dignidad como libertad se presenta como contingente, y se posee en la medida en que se es capaz de tomar

67 Rao, Neomi, "Three Concepts of Dignity in Constitutional Law", Notre Dame Law Review, 2011, pp. 183-272.

68 Barroso, Luis Roberto, "Here, There, and Everywhere: Human Dignity in Contemporary Law and the Transnational Discourse", Boston College International and Comparative Law Review, vol. 35, 2012, pp. 331-393.

69 Carozza, Paolo, "Human Dignity and Judicial Interpretation of Human Rights: A Reply”, European Journal of International Law, vol.19, núm. 5, 2008, pp. 931-944.

70 Meltzer Henry, op. cit. 
decisiones con autonomía. Se la ha usado para legitimar decisiones personales individuales en temas controversiales vinculados con la sexualidad y la vida. La dignidad como integridad personal se vincula con la teoría de la virtud, y tiene que ver con la integridad como condición para perfeccionarse. Se ha utilizado para proteger la reputación y evitar tratos o intrusiones degradantes o humillantes (por ejemplo, la realización de un allanamiento de forma intrusiva y violenta o la obligación de realizar un análisis de orina de trabajadores de ciertas empresas con otra persona al lado escuchando). Finalmente, la dignidad como virtud colectiva está relacionada con la totalidad de la vida humana en una determinada sociedad, y su protección puede llegar a limitar la autonomía personal, en favor de la dignidad o de la virtud colectiva. Se ha usado contra la tortura, la práctica de arrojar enanos, la prostitución, la esclavitud, la pena de muerte, las condiciones carcelarias, y la práctica del aborto por nacimiento parcial. ${ }^{71}$ Este autor sigue la teoría lingüística de Wittgenstein, según la cual hay lenguajes naturales y otros referenciales (como la geometría), entendiendo que solo estos últimos pueden tener significados fijos. Considera que la dignidad entonces no es un concepto, sino muchas concepciones, que varían de acuerdo con el contexto. Y para saber cuáles son esas concepciones, hay que estudiar cómo se usa el término en el lenguaje.

Otra investigación publicada en el contexto norteamericano es la de Goodman, quien estudia la dignidad en la jurisprudencia constitucional de la Corte Suprema de los Estados Unidos y se refiere a ella como un "valor constitucional", que subyace ante algunos reclamos constitucionales, y propone estándares para determinar cuándo las demandas de la dignidad deben prevalecer. $^{72}$

También podemos mencionar a Jackson, para quien la dignidad funciona como un concepto básico unificador que se vincula tanto con las garantías de los derechos y libertades civiles negativos como con los conceptos positivos de derechos humanos para alcanzar adecuadamente las necesidades básicas de la vida. ${ }^{73}$

En un trabajo de 2017, Shulztiner aborda los desafíos que plantea el concepto de dignidad humana para la toma de decisiones judiciales, y pro-

\footnotetext{
71 Idem.

72 Goodman, Maxine, "Human Dignity in Supreme Court Constitutional Jurisprudence”, Nebraska Law Review, 2006, pp. 740-794.

73 Jackson, Vicki, "Constitutional Dialogue and Human Dignity: States and Transnational Constitutional Discourse", Montana Law Review, V. 65, 2004, pp. 15-40.
} 
pone cuatro principios para su uso en tal ámbito: usar el concepto con estricta relación a la ley escrita; definir el concepto y su significado en las sentencias; ser consistentes en el uso del concepto en presentes y futuras decisiones, y usar el concepto únicamente para el progreso de los derechos humanos. $^{74}$

Glensy indaga sobre el sentido del "derecho a la dignidad" en el contexto de Estados Unidos de América, y enuncia cuatro teorías sobre los usos de este concepto: el enfoque de los derechos positivos, que considera a la dignidad como un derecho sustantivo accionable; el de los derechos negativos (o de no interferencia), de modo que la dignidad funciona como una norma de soporte; el enfoque de refuerzo, en virtud del cual la dignidad tiene un uso heurístico para reforzar otros derechos, y el enfoque expresivo, en el que la dignidad es presentada como un valor retórico. ${ }^{75}$

En Canáda, Goubau considera que hay un uso muy frecuente y creciente del término "dignidad humana" en la legislación y la jurisprudencia, y encuentra las siguientes connotaciones del término: como un elemento de la estima personal que debe ser respetado por otros; como un límite a ciertas acciones, fundado en la común humanidad y la dignidad como expresión de la autonomía individual. ${ }^{76}$

En el contexto alemán de posguerra, el concepto de dignidad humana ha sido fundamental, ya que ha sido incorporado al artículo 1 de la Constitución (también conocida como "Ley Fundamental de Bonn") luego de los horrores de la Segunda Guerra Mundial. ${ }^{77}$ En la literatura italiana se destacan los trabajos del profesor Viola ${ }^{78}$ y la profesora Malvestiti, ${ }^{79}$ entre otros. ${ }^{80}$

74 Shulztiner, Doron, "Human Dignity in Judicial Decisions: Principles of Application and the Rule of Law", Cardozo Journal of International and Comparative Law, vol. 25, 2017, pp. 435-481.

75 Glensy, Rex, “The Right to Dignity”, Columbia Human Rights Law Review, vol. 43, 2011, pp. 65-142.

76 Goubau, Dominique, "Dignity in Canadian Law, a Popular but Ambiguous Notion”, Ius Gentium, vol. 71, 2018, pp. 191-201.

77 Broß, Siegfried, "Die Würde des Menschen bleibt unantastbar", en Robertson-von Trotha, Caroline., 60 Jahre Grundgesetz Nomos, 2009, pp. 41-51.

78 Viola, Francesco, "Lo statuto normativo della dignità umana", en Abignente, Angelo y Scamardella, Francesca (eds.). Dignità della persona. Riconoscimento dei diritti nella società multiculturali, Napoli, Editoriale Scientifica, 2013, pp. 283-295.

79 Malvestiti, op. cit.

80 Becchi, Paolo, "Dignità umana", en Pomarici, Ulderico (cur.), Filosofia del diritto. 
En Inglaterra, a pesar de ser un país sin una Constitución escrita o una tradición de codificación, los tribunales han invocado la dignidad con relación a los derechos de los presos y la condena perpetua; en materia laboral, con relación a la dignidad del empleado y las condiciones de trabajo, y en relación con la no discriminación, por orientación sexual ${ }^{81}$ En este sentido, Callus distingue dos grandes usos: la dignidad como principio de respeto por el intrínseco valor de cada ser humano, y la dignidad como principio al servicio de los derechos subjetivos, con particular referencia a la vida privada y la calidad de vida. Según este autor, en los últimos tiempos en ese país se ha pasado de una visión más comunitaria de la dignidad hacia una visión más liberal. ${ }^{82}$

En España, podemos mencionar un trabajo que profundiza en la dignidad como "valor constitucional" explícitamente presente en el artículo 10.1 de la Constitución, afirmando que ha cumplido tres funciones: una función fundamentadora del orden político, una función promocional y una función hermenéutica. ${ }^{83}$

La producción académica francesa también incluye trabajos de investigación sobre la dignidad similares a los aquí propuestos, entre los que se destacan el de Burgorgue-Larsen — centrado en la dignidad según los jueces europeos, de tribunales tanto domésticos como regionales de derechos humanos— ${ }^{84}$ Otros artículos científicos exploran el concepto de la

Concetti fondamentali, Torino, Giappichelli, 2007, pp. 153-181; Mastropietro, Andrea. "Diritto e dignità umana", Rivista internazionale di Filosofia del Diritto, V.2, 2010, 241261; Berardo, Fiammeta, "La dignitá umana è intangibile. il dibattito costituente sull 'art. 1 del Grundgesetz", Quaderni costituzionali, 2006, pp. 387-398; Mattioni, Angelo, "Profili costituzionali della dignità umana", Jus, 2008, pp. 251-291; Monaco, Giuseppe, "La tutela della dignità umana: sviluppi giurisprudenziali e difficoltà applicative", Politica del diritto, 2011, pp. 45-77; Piciocchi, Cinzia, La dignità come rappresentazione giuridica della condizione umana, Padova, CEDAM, 2013; Rolla, Giancarlo, "Il valore normativo del principio della dignità umana. Brevi considerazioni alla luce del costituzionalismo iberoamericano", Diritto pubblico comparato ed europeo, 2003, pp. 1870-1880.

81 Callus, Thérèse "Towards a Libertarian Application of Dignity in English Law: A Case Law Analysis”, Ius Gentium, V.71, 2018, pp. 129-140.

82 Callus, op. cit.

83 Batista Jiménez, Fernando, "La dignidad de la persona en la Constitución española: naturaleza jurídica y funciones", Cuestiones Constitucionales. Revista Mexicana de Derecho Constitucional, 2006, pp. 3-20.

84 Burgorgue-Larsen, Laurence, La dignité saisie par les juges en Europe, Anthemis, 2011. 
dignidad de un modo más general, como concepto jurídico ${ }^{85}$ Finalmente, unos más lo consideran en relación con aspectos específicos. ${ }^{86}$

Barak profundiza en el uso del término "dignidad" en la Corte Suprema de Israel, y distingue la dignidad como valor constitucional de la dignidad como derecho constitucional. ${ }^{87}$ Ahora bien, en cuanto derecho constitucional, Barak señala el problema del "solapamiento" de la dignidad con otros derechos y trata de identificar el área que cubre la dignidad, para distinguirla del contenido de los otros derechos. Explica Barak que para la Corte Suprema de Israel la dignidad es un derecho que enmarca a otros derechos o un "derecho-madre" ("framework right" y "mother-right"). ${ }^{88}$

Un estudio publicado en 2018 da cuenta de los usos de la dignidad en China, y concluye que se trata de un concepto controvertido por razones semánticas vinculadas con las distintas traducciones del término. La dignidad personal mencionada en leyes positivas no puede ser entendida como un principio constitucional que sirva de base al régimen político o como principio fundante del ordenamiento jurídico, y en los tribunales la dignidad viene protegida como parte del derecho al honor o un derecho general a la personalidad. ${ }^{89}$

En el plano regional, podemos citar el trabajo de Chávez-Fernández Postigo, quien analiza algunas sentencias del Tribunal Constitucional peruano en torno a la forma de concebir la dignidad como fundamento de los derechos humanos. En el estudio, constata que el Tribunal Constitucional reconoce el fundamento de los derechos humanos en la dignidad humana, pero también concibe a la dignidad como un derecho autónomo. El jurista peruano señala que dado que "la dignidad es portadora de un contenido ético-jurídico amplio que incluye el de todos los derechos fundamentales -implícitos y explícitos - que sustenta y la expresan”, parece difícil jus-

85 Fierens, Jacques, "La dignité humaine comme concept juridique", Journal des tribunaux, 2002, p. 577-582; Menke, Christoph, "De la dignité de l'homme à la dignité humaine : le sujet des droits de l'homme", Revue franco-allemande de sciences humaines et sociales, V. 3, 2009, pp.1-20.

86 Maubernard, Christophe, "Le droit fondamental à la dignité humaine en droit communautaire: la brevetabilité du vivant à l'épreuve de la jurisprudence de la Cour de Justice", Revue trimestrielle des droits de l'homme, V. 54, 2003, pp. 483-513.

87 Barak, Aharon, "Human Dignity: The Constitutional Value and the Constitutional Right", Proceedings of the British Academy, V. 192, 2013, pp. 361-380.

88 Idem.

89 Zhang, Li, "The Emergence of Human Dignity in China: from a Private Right to a Constitutional Principle”, Ius Gentium, V. 71, 2018, pp. 231-244. 
tificar ese contenido autónomo. También observa que el Tribunal entiende a la dignidad desde dos concepciones que aparecen en tensión o antagonismo: la idea de una mera autonomía con cierta raigambre kantiana y la idea de una dignidad referida al ser u ontológica. ${ }^{90}$

En Argentina, podemos mencionar el trabajo de Estela Sacristán, quien luego de una pormenorizada recorrida por las menciones al término "dignidad" en el ordenamiento jurídico argentino analiza los usos que hace la CSJN sobre el término, tomando como eje las acepciones del término brindadas por el Diccionario de la lengua española:

(i) cualidad de digno (entendiéndose, por digno, merecedor de algo); correspondiente, proporcionado al mérito y condición de alguien o algo; que tiene dignidad o se comporta con ella; propio de la persona digna; que puede aceptarse o usarse sin desdoro, es decir, sin menoscabo en la reputación o el prestigio (salario digno, vivienda digna); de calidad aceptable; (ii) excelencia, realce; (iii) gravedad y decoro de las personas en la manera de comportarse; (iv) cargo o empleo honorífico y de autoridad; (v) en las catedrales y colegiatas, prebenda $-v$. gr., beneficio eclesiástico — que corresponde a un oficio honorífico y preeminente; prebenda del arzobispo u obispo; (vi) en las órdenes militares de caballería, cargo de maestre, trece, comendador mayor, clavero, etc. ${ }^{91}$

\section{UNA PROPUESTA DE SISTEMATIZACIÓN DE LOS USOS DE LA DIGNIDAD}

Luego de esta revisión de las clasificaciones sobre los usos de la dignidad que realizan los distintos autores, ya sea en su análisis de los cuerpos normativos como de los usos que realizan los tribunales, internacionales o nacionales, esbozamos a continuación una propuesta de sistematización, que constituye la base para el futuro análisis de los usos del término que realiza la Corte IDH, siguiendo cuatro criterios: a) dignidad en función del sujeto o elemento impersonal; b) dignidad en relación con la ponderación

90 Chávez Fernández Postigo, José, La dignidad como fundamento de los derechos humanos en las sentencias del Tribunal Constitucional peruano: la tensión entre la mera autonomía y la libertad ontológica, Lima, Palestra, 2012.

91 Sacristán, Estela, "El concepto de dignidad humana en la jurisprudencia de la Corte Suprema de Justicia de la Nación”, Prudentia Iuris, núm. 84, 2017, p. 44. 
en la implementación de derechos; c) dignidad en torno a la concepción del individuo; d) según el rol de la dignidad. Se trata de criterios que no necesariamente se excluyen, y que pueden resultar complementarios según el uso que se haya dado al término "dignidad".

\section{Dignidad en función del sujeto o elemento impersonal}

Una primera distinción sobre los usos de la dignidad se vincula al sujeto del que se predica la cualidad de "digno". En tal sentido, podemos distinguir los siguientes usos:

- La dignidad como estatus institucional: se aplica a cargos, Estados, personas jurídicas en general. Meltzer refiere a los orígenes del término "dignidad" en la antigua Roma, y cómo se vinculaba con las posiciones más destacadas en la jerarquía social. También señala la recepción de este uso en el lenguaje en Inglaterra en 1225 vinculado con el rango y la jerarquía. ${ }^{92}$ Tal origen permite comprender este uso que, aunque suele aparecer en diferentes documentos normativos, no es relevante a la hora de ver la relación con los derechos. Sin embargo, no puede obviarse por cuanto su inclusión permite ver en qué medida aparece (si es que se utiliza) o si ha sido dejado de lado por la Corte IDH.

- La dignidad como nota de las personas humanas: es el uso preponderante en los documentos internacionales de derechos humanos. Puede ser intrínseca o ser reconocida o atribuida en virtud de otra fuente según se explicite y según el criterio en torno a la concepción del individuo.

- La dignidad aplicada a otros elementos, que no son personas humanas, personas jurídicas o cargos. En este uso podemos ubicar el caso de la dignidad de los muertos en el fallo Comunidad Moiwana vs. Suriname de la Corte IDH (2005). Este uso puede ser de utilidad para observar cómo la concepción de este término puede ampliarse para receptar otras visiones culturales en la aplicación de derechos que podrían ser caracterizados como "occidentales".

92 Meltzer Henry, op. cit. 


\section{Dignidad en relación con la ponderación} en la implementación de derechos

Tomando como criterio el uso en relación con la ponderación en la implementación de los derechos, podemos distinguir:

- Uso ampliatorio: el concepto sirve para potenciar, fortalecer o respaldar el derecho que acompaña. Por ejemplo, en diversas ocasiones se puede encontrar la mención a "vida digna" o a "condiciones de trabajo dignas" o a "vivienda digna". Shulztiner y Carmi ofrecen distintos ejemplos de estos usos, ${ }^{93}$ mientras que McCrudden pone como ejemplo de este uso de la dignidad a la sentencia del 19 de noviembre 1999 de la Corte Interamericana de Derechos Humanos en el caso de los "Niños de la Calle" (Villagrán Morales y otros) vs. Guatemala (fondo), en el que la Corte sostuvo que "el derecho fundamental a la vida comprende, no sólo el derecho de todo ser humano de no ser privado de la vida arbitrariamente, sino también el derecho a que no se le impida el acceso a las condiciones que le garanticen una existencia digna" (n. 144). ${ }^{94}$

- Uso limitador: el concepto se utiliza para limitar los derechos que acompaña, para graduarlos en forma restrictiva o rechazar una demanda. Si bien, como se ha mencionado en la revisión bibliográfica, no es un uso frecuente, sí es posible hallar casos en la limitación de la libertad de expresión cuando afecta la dignidad humana de otro u otros sujetos (por ejemplo, la prohibición de un discurso de odio racial). Por ejemplo, según Goubau, la Corte Suprema de Canadá ha recurrido al principio de la dignidad humana para decidir sobre la legalidad de la prohibición o restricciones a la prostitución, a las publicaciones obscenas, al suicidio asistido o al acceso del acusado a información personal sobre la demanda en un caso de delito contra la integridad sexual. ${ }^{95}$ Meltzer menciona casos de la Suprema Corte de Israel que recurrió a la protección de la dignidad humana para abordar un caso referido al problema

\footnotetext{
93 Shulztiner y Carmi, op. cit.

94 McCrudden, op. cit.

95 Goubau, op. cit.
} 
de la pornografía en el cine o para limitar la libertad de expresión a fin de poner fin al racismo como una afrenta a la dignidad humana. ${ }^{96}$

\section{Dignidad en torno a la concepción del individuo}

El tercer criterio que proponemos para clasificar los usos del término refiere a la concepción del individuo subyacente al concepto de dignidad. Así, encontramos tres posibles usos:

- Dignidad como igualdad formal en libertad: se funda en la autonomía de los sujetos, y se reconoce a quienes tienen capacidad para tomar decisiones o formar un plan de vida. La atribución de un sentido basado en la igualdad formal o de corte liberal al término "dignidad" implica que éste actúa como un límite al actuar de terceros, y, en particular, del Estado que pudiera impedir el libre ejercicio de los propios derechos. Es decir, se trata de erradicar las interferencias de otros en materias que hacen al ejercicio irrestricto de las libertades individuales. Así, la dignidad es un fundamento para la autonomía personal, y se considera respetada cuando el individuo puede perseguir sus propios fines y metas (Rao, 2011). Este tipo de criterio, si bien expone una característica de la dignidad, no logra dar una definición de ella, ya que se concentra en los efectos prácticos de su reconocimiento en relación con el ejercicio de los derechos que se encuentran cuestionados en el caso concreto que llega ante los estrados.

- Dignidad como valor sustantivo: implica la consideración de una moral sustantiva y de la opción por un modelo de vida virtuoso que guía la concreción de una vida digna o de un trato digno. En contraste con el sentido anterior, que es pluralista, el sentido sustantivo promueve algún tipo de concepción de lo que se considera bueno, ya sea por estimar correcta la acción en sí misma o en relación con un fin externo a la conducta, y que se concretaría de manera mediata. Según Rao, las visiones sustantivas de la dignidad comprenden una visión particular sobre lo que constituye el

96 McCrudden, op. cit. 
bien para el ser humano y qué es aquello que permite que el individuo y la sociedad florezcan. ${ }^{97}$ Este uso de la dignidad ha estado vinculado, por ejemplo, a decisiones judiciales que avalaron la proscripción de la prostitución.

- Dignidad con concepto o fundamento no explícito: se puede constatar un uso de la dignidad que aspira a tutelar un mínimo de bienestar físico y psicológico de los sujetos para que puedan desarrollar su vida, pero no explicita en qué está fundada la dignidad. Este uso presupone un acuerdo en los aspectos prácticos de los derechos humanos o la dignidad, pero evita ingresar en el habitualmente controversial terreno del fundamento de tal acuerdo. Maritain relata, como ejemplo, que en una de las reuniones de la Comisión Nacional francesa de la UNESCO que discutía los derechos del hombre se señaló que había acuerdo en la redacción de los derechos entre personas partidarias de posturas claramente antagónicas siempre que no se les pregunte por qué están de acuerdo. ${ }^{98}$ En torno a la prohibición de las torturas podemos encontrar un claro ejemplo de este acuerdo sin que se explicite un fundamento de la dignidad.

\section{Según el rol de la dignidad}

El cuarto criterio refiere al rol que cumple la dignidad en relación con los derechos humanos. Los usos que encontramos en la doctrina son:

- La dignidad como fundamento de derechos: como explica Glendon, a partir de la Declaración Universal de Derechos Humanos, la dignidad se presenta como el valor fundante del sistema de protección de los derechos. En este sentido, advertimos distintos matices en este sentido, pues la dignidad puede ser reconocida como fundamento en términos genéricos, como principio fundante o como valor inspirador. Malvestiti realiza una sistematización interesante de las formas en que la dignidad se entiende como "norma suprema" y cómo ello se vincula también con la

\footnotetext{
97 Rao, "Three Concepts of Dignity in Constitutional Law".

98 Maritain, Jacques, "Introduction", en Human Rights: Comments and Interpretations. A Symposium edited by UNESCO, Paris, UNESCO, 1948, pp. I-IX.
} 
interpretación y los modos de concreción de la dignidad. ${ }^{99} \mathrm{El}$ trabajo de Chávez-Fernández Postigo ofrece una indagación incisiva sobre este uso de la dignidad por el Tribunal Constitucional peruano. ${ }^{100}$

- La dignidad como derecho a la dignidad: en diversos documentos y sentencias se menciona la dignidad como derecho de los sujetos. El trabajo de Barak realiza un agudo estudio de la dignidad como derecho y los problemas que se plantean en cuanto a sus alcances por la superposición que presenta este "derecho" con otros derechos con los que está vinculado. ${ }^{101}$ También debemos mencionar los cuatro enfoques que propone Glensy sobre el derecho a la dignidad y sus usos por parte de los tribunales. ${ }^{102}$

\section{CONSIDERACIONES FINALES}

El término "dignidad" es uno de los más relevantes en el marco de la protección internacional de los derechos humanos. Tan es así, que aparece reiteradamente en los principales documentos fundacionales de los diferentes sistemas. Asimismo, ha sido una preocupación de diversos doctrinarios esclarecer qué debe entenderse y qué se entiende por dicha noción. En este trabajo hemos presentado diferentes clasificaciones con la expectativa de poder mostrar la pluralidad semántica posible que encierra la "dignidad". En particular, hemos intentado concentrarnos en los sentidos que parecieran subsumir gran parte de las categorías postuladas por los autores.

Esta clasificación opera como una conclusión provisoria, que orientará la tarea de indagar los usos que hace del término "dignidad" la Corte IDH. Una vez realizada esa investigación, se podrá verificar si la sistematización propuesta ha sido útil o si hace falta alguna rectificación. Ello sin perjuicio de enfatizar que el objetivo central de la investigación será determinar si la Corte IDH realiza un uso unívoco de la noción de dignidad o bien si hay

99 Malvestiti, op. cit.

100 Chávez-Fernández Postigo, op. cit.

101 Barak, op. cit.

102 Glensy, op. cit. 
una variación semántica que genera problemas al momento de cumplir la tarea de resolver las controversias que se le plantean.

Como puede notarse, en el estado de la cuestión existen diversas formas de entender la dignidad en la práctica jurídica, es decir, ya sea en la normativa general o en las sentencias de los casos concretos. No obstante, a pesar de los diferentes usos, es posible que existan puntos en común. En abstracto, podemos ver lo dificultoso que puede resultar diferenciar tajantemente algunas de las clasificaciones que hemos propuesto. Creemos que en el análisis de los casos contenciosos y opiniones consultivas de la Corte IDH encontraremos solapamientos de las categorías antedichas, tanto si este organismo usa de manera indistinta como diferente al concepto de dignidad. Lejos de resultar un inconveniente, tal vez esto permita encontrar un sentido focal desde el cual podamos identificar definiciones analógicas. Precisamente, la búsqueda de un común denominador a partir de resaltar la diversidad (al menos en el plano teórico, en la investigación constataremos qué sucede en los hechos) puede ser el mayor aporte de las categorías que hemos propuesto y del estudio de los fallos y opiniones de la Corte IDH sobre la dignidad.

\section{REFERENCIAS BIBLIOGRÁFICAS}

AMEZCUA, Luis, "Algunos puntos relevantes sobre la dignidad humana en la Jurisprudencia de la Corte Interamericana de Derechos Humanos", Revista Iberoamericana de Derecho Procesal Constitucional, 8, 2007.

Andorno, Roberto, "The Paradoxical Notion of Human Dignity", Rivista Internazionale di Filosofia Del Diritto, 78, 2001.

BARAK, Aharon, "Human Dignity: The Constitutional Value and the Constitutional Right", Proceedings of the British Academy, 192, 2013.

BARroso, Luis Roberto, "Here, There, and Everywhere: Human Dignity in Contemporary Law and the Transnational Discourse", Boston College International and Comparative Law Review, 35, 2012.

BATista JimÉneZ, Fernando, "La dignidad de la persona en la Constitución española: naturaleza jurídica y funciones", Cuestiones Constitucionales. Revista Mexicana de Derecho Constitucional, 2006, disponible en: https://doi.org/10.22201/iij.24484881e.2006.14.5750. 
BeCCHI, Paolo, "Dignità umana", in Ulderico Pomarici (cur.), Filosofia del diritto. Concetti fondamentali, Torino, Giappichelli, 2007.

BELOFF, Mary y Clérico, Laura, "Derecho a condiciones de existencia digna y situación de vulnerabilidad en la jurisprudencia de la Corte InterAmericana", Estudios Constitucionales, 14 (2016), disponible en: https://doi.org/10.4067/S0718-52002016000100005.

BERARDO, Fiammetta, "La dignitá umana è intangibile. il dibattito costituente sull'art. 1 del Grundgesetz", Quaderni costituzionali, 2006.

Bohórquez MonsAlve, Viviana y Aguirre Román, Javier, "Las tensiones de la dignidad humana: conceptualización y aplicación en el derecho internacional de los derechos humanos", Sur. Revista Internacional de Derechos Humanos, 6, 2009.

BROß, Siegfried, "Die Würde des Menschen bleibt unantastbar", en CAROLINE Y. RoBERTSON-von TrothA (ed.), 60 Jahre Grundgesetz, Nomos, 2009, disponible en: https://doi.org/doi.org/10.5771/97838452203 45-41.

Burgorgue-LARSEN, Laurence, La dignité saisie par les juges en Europe, Anthemis, 2011.

CALlus, Thérèse, "Towards a Libertarian Application of Dignity in English Law: A Case Law Analysis”, Ius Gentium, 71, 2018, disponible en: https://doi.org/10.1007/978-3-319-99112-2_9.

CALO, Zacharie, "Human Dignity and Health Law: Personhood in recent bioethical debates", Notre Dame JL Ethics \& Pub. Pol'y, 1, 2012.

CAnÇAdo Trindade, Antonio Augusto y César Barros Leal (eds.), El respeto a la dignidad de la persona humana, Fortaleza, Instituto Brasileño de Derechos Humanos, 2015, disponible en: http://ibdh.org.br/ wp-content/uploads/2016/10/2015f-book.pdf.

CArozzA, P. G., "Human Dignity and Judicial Interpretation of Human Rights: A Reply", European Journal of International Law, 19, 2008, disponible en: https://doi.org/10.1093/ejil/chn059.

Chávez-Fernández Postigo, José, La dignidad como fundamento de los derechos humanos en las sentencias del Tribunal Constitucional peruano, Lima-Arequipa, Palestra Editores-Universidad Católica San Pablo, 2012.

Chávez Fernández Postigo, José, La dignidad como fundamento de los derechos humanos en las sentencias del Tribunal Constitucional 
peruano: la tensión entre la mera autonomía y la libertad ontológica, Lima, Palestra, 2012-

Consejo de Europa, Carta Social Europea, Estrasburgo, 1961, disponible en: https://www.acnur.org/fileadmin/Documentos/BDL/2002/1934. pdf?file $=t 3 /$ fileadmin $/$ Documentos $/ B D L / 2002 / 1934$.

Consejo de Europa, Convenio Europeo para la Protección de los Derechos Humanos y de las Libertades Fundamentales, 1950, disponible en: https://www.echr.coe.int/Documents/Convention_SPA.pdf.

Consejo DE EuROPA, Protocolo no. 13 al Convenio para la Protección de los Derechos Humanos y de las Libertades Fundamentales, relativo a la abolición de la pena de muerte en cualquier circunstancia, 2002, disponible en: https://www.echr.coe.int/Documents/Convention_SPA.pdf.

CostA, Jean-Paul, "Human Dignity in the Jurisprudence of the European Court of Human Rights", Understanding Human Dignity, Oxford, British Academy, 2013, disponible en: https://doi.org/10.5871/bacad/9780197265642.003.0022.

DiLley, Stephen y J. PALPANT, Nathan, Human Dignity in Bioethics: from Worldviews to the Public Square, ed. Stephen Dilley y Nathan J. Palpant. London, Routledge, 2012.

Federmann, Falco, Die Konstitutionalisierung der Europäischen Union. Überlegungen vor dem Hintergrund des andauernden europäischen Verfassungsprozesses, Köln, Eul Verlag, 2007.

Feuillet-Liger, Brigitte, "The Case for a Limited Use of Dignity as a Legal Principle", Ius Gentium, 71, 2018, disponible en: https://doi. org/10.1007/978-3-319-99112-2_22.

FIERENS, Jacques, "La dignité humaine comme concept juridique", Journal des tribunaux, 2002, disponible en: http://orbi.ulg.ac.be/bitstream/2268/200677/1/La dignité humaine comme concept juridique.pdf [accedido 4 julio 2017].

FISCHER, Joschka, "Vom Staatenverbund zur Föderation - Gedanken über die Finalität der europäischen Integration", Intergation, 23, 2000, disponible en: http://www.jstor.org/stable/24220578.

FranzIUS, Claudio, "Die Europäische Dimension des Gewährleistungsstaates", Der Staat, 45, 2006.

Glendon, Mary Ann, "Knowing the Universal Declaration of Human Rights", The Notre Dame Law Review Review, 73, 1998. 
Glensy, Rex D., "The Right to Dignity", Columbia Human Rights Law Review, 43, 2011.

Goodman, Maxine D., "Human Dignity in Supreme Court Constitutional Jurisprudence", Nebraska Law Review, 2006.

Goubau, Dominique, "Dignity in Canadian Law, a Popular but Ambiguous Notion”, Ius Gentium, 71, 2018, disponible en: https://doi. org/10.1007/978-3-319-99112-2_14.

Grabenwarter, Christoph y Struth, Katharina, "Justiz- und Verfahrensgrundrechte", en D. EHLERS (ed.), Europäische Grundrechte und Grundfreiheiten, Göttingen, De Gruyter, 2014.

MAC-Gregor, Eduardo y Pelayo Möller, Carlos María, "Preámbulo", en Christian SteIner y Patricia UriBe (eds.), Convención Americana sobre Derechos Humanos comentada, 2014.

GREWE, Constance, "La dignité de la personne humaine dans la jurisprudence de la Cour européenne des droits de l'homme", Revue générale du droit, 2014.

GROS ESPIELL, Héctor, "La dignidad humana en los instrumentos internacionales sobre derechos humanos", Anuario de Derechos Humanos, 4, 2003.

HERRERA, Daniel Alejandro, La persona y el fundamento de los derechos humanos, Buenos Aires, EDUCA, 2012.

Hoyos CASTAÑEDA, Ilva Myriam, De la dignidad y de los derechos humanos, Bogotá, Universidad de la Sabana, 2005.

IBÁÑEZ RIVAS, Juana María, "La dignidad humana y los derechos económicos, sociales y culturales en la jurisprudencia contenciosa de la Corte Interamericana de Derechos Humanos", en Antonio Augusto CANÇADO TRINDADE y César BARRos LEAL (eds.), El respeto a la dignidad de la persona humana, Fortaleza, Instituto Brasileño de Derechos Humanos, 2015.

JACKSON, Vicki C., "Constitutional Dialogue and Human Dignity: States and Transnational Constitutional Discourse", Montana Law Review, 65, 2004.

KATEB, George, Human Dignity, Cambridge, Harvard University Press, 2011.

KLATT, M., "Juristische Hermeneutik”, en Handbuch Rechtshilosophie, J. B. Metzler, 2017. 
KUTEYNIKOV, Alexander, y BOYASHOV, Anatoly, "Dignity before the European Court of Human Rights", en Edward SIEH y Judy MCGREGOR (eds.), Human Dignity: Establishing Worth and Seeking Solutions, London, Palgrave MacMillan 2017, disponible en: https://doi. org/10.1057/978-1-137-56005-6_6.

LANDA, César, "Dignidad de la persona humana", en Antonio Augusto CANÇAdo TRINidAde y César BARRos LeAl (eds.), El respeto a la dignidad de la persona humana, Fortaleza, Instituto Brasileño de Derechos Humanos, 2015, disponible en: http://ibdh.org.br/wp-content/ uploads/2016/10/2015f-book.pdf.

MALVESTITI, Barbara, La dignità umana dopo la "Carta di Nizza”, Napoli-Salerno, Orthotes Editrice, 2015.

MARITAIN, Jacques, "Introduction", Human Rights: Comments and Interpretations. A Symposium edited by UNESCO, Pris, UNESCO, 1948.

MASsini Correas, Carlos Ignacio, Filosofía del derecho - I - El derecho, los derechos humanos y el derecho natural, 2a. ed., Buenos Aires, Lexis-Nexis, 2005.

MASTROPIETRO, Andrea, "Diritto e dignità umana", Rivista Internazionale di Filosofia del Diritto, 2, 2010.

Mattioni, Angelo, "Profili costituzionali della dignità umana", Jus, 2008.

MAUBERnARD, Christophe, "Le droit fondamental à la dignité humaine en droit communautaire : La brevetabilité du vivant à l'épreuve de la jurisprudence de la Cour de Justice", Revue trimestrielle des droits de l'homme, 54, 2003, disponible en: http://www.rtdh.eu/pdf/2003483.pdf [accedido 4 julio 2017].

MCCRUDDEN, Christopher, "Human Dignity and Judicial Interpretation of Human Rights", European Journal of International Law, 19, 2008, disponible en: https://doi.org/10.1093/ejil/chn043.

MELtzer Henry, Leslie, "The Jurisprudence of Dignity”, University of Pennsylvania Law Review, 160, 2011.

MenKe, Christoph, "De la dignité de l'homme à la dignité humaine : le sujet des droits de l'homme", Revue franco-allemande de sciences humaines et sociales, 3, 2009.

Michael, Lucy, "Defining Dignity and Its Place in Human Rights", The New Bioethics, 20, 2014, disponible en: https://doi.org/10.1179/20502 $87714 z .00000000041$. 
MONACO, Giuseppe, "La tutela della dignità umana: sviluppi giurisprudenziali e difficoltà applicative", Politica del diritto, 2011.

OEA, Convención Americana sobre Derechos Humanos, 1969, disponible en: https://www.oas.org/dil/esp/tratados_b-32_convencion_americana_sobre_derechos_humanos.htm.

OEA, Convención Interamericana para la Prevención, Sanción y Erradicación de la Violencia, 1994, disponible en: https://www.oas.org/juridico/spanish/tratados/a-61.html.

OEA, Convención Interamericana para Prevenir, Sancionar y Erradicar la Violencia contra la Mujer, 1994, disponible en: http://www.corteidh. or.cr/sitios/libros/todos/docs/documentosbasicos2018.pdf.

OEA, Convención Interamericana para Prevenir y Sancionar la Tortura, 1987, disponible en: https://www.oas.org/juridico/spanish/tratados/ a-51.html.

OEA, Convención Interamericana sobre Desaparición Forzada de Personas, 1994, disponible en: https://www.oas.org/juridico/spanish/trata dos/a-60.html.

OEA, Declaración Americana de los Derechos y Deberes del Hombre, 1948, disponible en: http://www.oas.org/es/cidh/mandato/Basicos/declaracion.asp.

OEA, Protocolo Adicional a la Convención Americana sobre Derechos Humanos en materia de Derechos Económicos, Sociales y Culturales, 1988, disponible en: https://www.oas.org/juridico/spanish/ tratados/a-52.html.

ONU, Carta de las Naciones Unidas (San Francisco, 1945), disponible en: https://www.un.org/es/charter-united-nations/.

ONU, Convención Internacional sobre los Derechos de las Personas con Discapacidad, 2006, disponible en: https://www.un.org/esa/socdev/ enable/documents/tccconvs.pdf.

ONU, Convención Internacional sobre los Derechos del Niño, 1989, disponible en: https://www.un.org/es/events/childrenday/pdf/derechos.pdf.

ONU, Declaración Universal de Derechos Humanos, 1948, disponible en: https://www.un.org/es/universal-declaration-human-rights/.

ONU, Pacto Internacional de Derechos Civiles y Politicos, 1976, disponible en: https://www.ohchr.org/SP/ProfessionalInterest/Pages/CCPR. aspx. 
ONU, Pacto Internacional de Derechos Económicos, Sociales y Culturales, 1976, disponible en: https://www.ohchrorg/SP/ProfessionalInterest/Pages/CESCR.aspx.

Organización para la UnidAd AfricAna, Carta Africana sobre Derechos Humanos y de los Pueblos, 1981, disponible en: https://www. acnur.org/fileadmin/Documentos/BDL/2002/1297.pdf.

ORganización PARA LA UNIDAD AFRICANA, Carta Africana sobre los Derechos y el Bienestar del Niño, 1990, disponible en: https://www. acnur.org/fileadmin/Documentos/BDL/2010/8025.pdf?view.

Pereira-Menaut, Antonio-Carlos y Pereira-SÁez, María-Carolina, "Human Dignity and European Constitutionalism. Flatus Vocis or Ratio Decidendi?", Ius Gentium, 52, 2016.

PICIOCCHI, Cinzia, La dignità come rappresentazione giuridica della condizione umana, Padova, CEDAM, 2013.

QuintanA, Eduardo, "Dignidad y deberes humanos", Prudentia Iuris2, 83, 2017.

RAO, Neomi, "On the Use and Abuse of Dignity in Constitutional Law", Columbia Journal of European Law, 2008.

RAO, Neomi, "Three Concepts of Dignity in Constitutional Law", Notre Dame Law Review, 2011.

RoLLA, Giancarlo, "Il valore normativo del principio della dignità umana. Brevi considerazioni alla luce del costituzionalismo iberoamericano", Diritto pubblico comparato ed europeo, 2003.

SACRISTÁN, Estela, "El concepto de dignidad humana en la jurisprudencia de la Corte Suprema de Justicia de la Nación", Prudentia Iuris, 84, 2017.

SHUlzTINER, Doron, "Human Dignity in Judicial Decisions: Principles of Application and the Rule of Law", Cardozo Journal of International and Comparative Law, 25, 2017.

ShulzTiner, Doron, y E. CARMI, Guy, "Human Dignity in National Constitutions: Functions, Promises and Dangers", American Journal of Comparative Law, 62, 2014, disponible en: https://doi.org/10.5131/ AJCL.2014.0003.

TORRALBA, Francesc, ¿Qué es la dignidad humana? Ensayo sobre Peter Singer, Hugo Tristram Engelhardt y John Harris, Barcelona, Herder, 2005.

Esta obra está bajo una Licencia Creative Commons

Atribución-NoComercial-SinDerivar 4.0 Internacional, IIJ-UNAM. 
Unión Europea, Carta de los Derechos Fundamentales de la Unión Europea, 2000, disponible en: $h t t p: / / w w w . e u r o p a r l . e u r o p a . e u / c h a r t e r / p d f /$ text_es.pdf.

VIOLA, Francesco, "Lo statuto normativo della dignità umana", en Angelo ABIGNENTE y Francesca ScAmardella (eds.), Dignità della persona. Riconoscimento dei diritti nella società multiculturali, Napoli, Editoriale Scientifica, 2013.

WALDRON, Jeremy, "Is Dignity the Foundation of Human Rights?", $N Y U$ School of Law, Public Law Research Paper, 12-73, 2013, disponible en: https://doi.org/10.2139/ssrn.2196074.

Wallace, H., "Die Dynamik des EU-Institutionengefüges", en M JACHTENFUCHS y B. KOHLER-KOCH (ed.), Europäische Integration, Springer Verlag, 2003.

ZHANG, Li, "The Emergence of Human Dignity in China: From a Private Right to a Constitutional Principle", Ius Gentium, 71, 2018, disponible en: https://doi.org/10.1007/978-3-319-99112-2_17.

Fecha de recepción: 26 de agosto de 2019.

Fecha de aceptación: 10 de noviembre de 2019.

Esta obra está bajo una Licencia Creative Commons Atribución-NoComercial-SinDerivar 4.0 Internacional, IIJ-UNAM. 